\title{
Beyond Single-Factor Affine Term Structure Models
}

\author{
Eva Ferreira \\ Universidad del País Vasco \\ Javier Gil-Bazo \\ Universidad Carlos III de Madrid
}

We would like to thank the editor René Garcia and two anonymous referees, whose comments, suggestions and insights greatly improved the paper. We also benefitted from valuable discussions by Gonzalo Rubio, Winfried Stute, Manuel Moreno, Eliseo Navarro, José-Manuel Campa and participants at II Jornadas de Estructura Temporal de Tipos de Interés and IX Foro de Finanzas, as well as seminar participants at Universidad Carlos III and Universidad del País Vasco. Thanks, finally, to Antonio Díaz for providing us with the data and to Monica Gago for her help. All remaining errors are the authors' sole responsibility. Eva Ferreira acknowledges the financial support provided by the Ministerio de Ciencia y Tecnología, grant BEC 2001-0636 and Javier Gil-Bazo acknowledges funding received from the Ministerio de Educación y Cultura, grant SEC 2001-1169.

Please address all correspondence to Javier Gil-Bazo, Departamento de Economía de la Empresa, Universidad Carlos III de Madrid, c/ Madrid 126, 28903 Getafe, Madrid (Spain). Email: javier.gil.bazo@uc3m.es, tel: +3491624 5844, fax: +34916249607. 


\begin{abstract}
This paper proposes a new approach to testing for the hypothesis of a single priced risk factor driving the term structure of interest rates. The method does not rely on any parametric specification of the state variable dynamics or the market price of risk. It simply exploits the constraint imposed by the no arbitrage condition on instantaneous expected bond returns. In order to achieve our goal, we develop a Kolmogorov-Smirnov test and apply it to data on Treasury bills and bonds for both the U.S. and Spain. We find that the single risk-factor hypothesis cannot be rejected for either dataset.
\end{abstract}

Keywords: single-factor term structure models, nonparametric estimation, bond risk premiums, Kolmogorov-Smirnov test.

JEL classification: C14; G13; E43; 


\section{Introduction}

Dynamic models of the term structure typically derive explicit formulas for default-free bond prices as a function of a set of parameters and a small number of state variables. This enables the pricing of discount and coupon bonds as well as bond derivatives at any point in time.

A particularly appealing class of dynamic term structure models is the affine family, studied in its general multivariate form by Duffie and Kan (1996). In these models, the short rate is assumed to be linear in the state variables, whose dynamics are governed by a multivariate diffusion with linear drift and linear variance structure. Duffie and Kan (1996) show that, if the price of risk for each factor is also linear in the factor diffusion, then zero-coupon bond prices are exponential affine in the state variable vector and yields-to-maturity are linear in the state variables.

Despite the popularity of affine term structure models, several authors have underlined the restrictive nature of the underlying assumptions ${ }^{1}$. Dai and Singleton (2000) note that the assumption of linear conditional variances for the state variables dynamics, implies the positivity of those state variables driving conditional variances, which must follow independent univariate square-root processes. Duffee (2002) also shows that reducing the number of risk factors in the conditional variance, enables a more flexible specification for market prices of risk (and therefore risk premiums) associated with nonvolatility risk factors. These trade-offs severely limit the ability of affine term structure models to simultaneously fit conditional interest means and volatilities of interest rate data, as shown by Dai and Singleton (2002).

Models encompassed in the quadratic class (see Ahn, Dittmar and Gallant, 2002) have emerged as a competing alternative to the affine class. In these models, the instantaneous rate is a quadratic function of the state variable vector, which follows a multivariate constant variance diffusion under 
the risk-neutral measure. Under these conditions, yields are also quadratic in the state variables. Brandt and Chapman (2002) have compared the empirical performance of both model classes and have concluded that quadratic term structure models are clearly superior to affine models in terms of fitting historical volatility.

The recent literature on dynamic term structure models therefore teaches us that lack of flexibility, necessary to achieve model tractability, comes at the cost of limited success in fitting interest rate data. In this paper, we build on this insight and reassess the ability of a single risk factor to explain the cross section of bond returns when no parametric restrictions are imposed on the state variable dynamics or the market price of risk. In particular, under the assumption that the state variable follows an Ito process with smooth drift and diffusion, we develop a new method to test for the hypothesis that exposure to a single priced risk factor is sufficient to explain differences in bond returns across maturities. The advantage of our approach is that model rejection cannot be attributed to any particular parametrization of the state variable conditional distribution or the market price of risk. Also, our test does not assume perfect identification between the short rate and the single state variable because the state of the system is not forced to depend on the short rate exclusively.

The test simply exploits the observation that instantaneous bond returns at any given point in time should be conditionally perfectly correlated in the presence of a single risk factor, so in order to prevent arbitrage, the instantaneous conditional expected excess return on any bond must be proportional to its exposure to the risk factor, which -from Ito's Lemma- is proportional to the bond return's diffusion.

Our testing procedure can be summarized as follows. First, instantaneous excess zero-coupon bond returns are approximated from daily data on bond prices of different maturities and the short 
rate. Next, the diffusion function is estimated nonparametrically for each bond. Finally, excess returns divided by the bond diffusions are computed. If the null hypothesis holds, excess returns per unit risk should be equal across maturities. However, since zero-coupon bond returns are generally observed with error, we reformulate our null hypothesis in terms of equality of conditional means. Formally, we derive a Kolmogorov-Smirnov test which presents two advantages with respect to existing methods: the test does not assume independent variables and it does not require a fixed design.

We apply our test to two different samples: one that corresponds to the Spanish market during the January 1993-December 2001 period, and another one consisting of U.S. interest rates in the April 1984-May 2003 period. Our results suggest that the single factor hypothesis cannot be rejected for either dataset. Using a longer series for the U.S. which covers 42 years of daily data, does not change the results substantially. This finding, rather than as a challenge to the multifactor nature of interest rates, should be seen as evidence that most of the risk premium in bond returns compensates investors for exposure to a single risk factor. In other words, risk premiums associated with additional factors are statistically hard to detect when only mild restrictions are imposed on the term structure model.

It should be noted that we are not the first to find that a single-factor model captures well the observed term structure dynamics. In a paper that is close in spirit to ours, Jeffrey et al. (2004) have developed a nonparametric test based on the term-structure of yield volatilities under a nonparametric time-homogeneous univariate Markov model. Consistently with our results, they cannot reject the null hypothesis for U.S. interest rate data in the 1961-1998 period.

The rest of the paper is organized as follows: Section 1 proposes a nonparametric testing method for the single-factor hypothesis. Section 2 explores the finite sample properties of the test. Section 
3 presents the empirical results. Finally, section 4 concludes. The derivation of the test, together with Monte Carlo results are provided in detail in the Appendix.

\section{A nonparametric test for the single-factor hypothesis}

The test we propose relies on a model where the underlying source of uncertainty in the economy, $X_{t}$, is represented by a continuous-time diffusion process. More specifically, the dynamics of $X_{t}$ is assumed to be governed by the following time-homogeneous stochastic differential equation:

$$
d X_{t}=\mu\left(X_{t}\right) d t+\sigma\left(X_{t}\right) d W_{t}
$$

where $W_{t}$ denotes a standard Wiener process and the functions $\mu(\cdot)$ and $\sigma(\cdot)$ are assumed to be at least twice differentiable.

Under the single risk factor assumption, unexpected changes in bond prices are entirely driven by shocks to this factor. Moreover, (1) assumes that the dependence on time is given only through the dependence on the risk factor $X_{t}$. Under this diffusion for the risk factor, it is feasible to derive the dynamics of the price of a bond with fixed time-to-maturity $T$, which we denote by $B_{T}\left(X_{t}\right)$. We assume that $B_{T}\left(t, X_{t}\right)$ is a smooth function of the risk factor and that it depends on $t$ only through its dependence on $X_{t}$; we thus have $B_{T}\left(t, X_{t}\right)=B_{T}\left(X_{t}\right)$.

Using Ito calculus, it can be shown that the process for a bond's price is governed by the following stochastic differential equation:

$$
\frac{d B_{T}\left(X_{t}\right)}{B_{T}\left(X_{t}\right)}=m_{T}\left(X_{t}\right) d t+s_{T}\left(X_{t}\right) d W_{t}
$$


where

$$
m_{T}\left(X_{t}\right) B_{T}\left(X_{t}\right)=\mu\left(X_{t}\right) B_{T}^{\prime}\left(X_{t}\right)+\frac{1}{2} \sigma^{2}\left(X_{t}\right) B_{T}^{\prime \prime}\left(X_{t}\right)
$$

and

$$
s_{T}\left(X_{t}\right) B_{T}\left(X_{t}\right)=\sigma(X) B_{T}^{\prime}\left(X_{t}\right)
$$

It follows that under the single factor assumption, the instantaneous returns on all bonds must be perfectly conditionally correlated and, therefore, to prevent arbitrage, their instantaneous risk premiums must be proportional to their sensitivities to the risk factor; that is, proportional to $B_{T}^{\prime}\left(X_{t}\right) / B_{T}\left(X_{t}\right)$, which determines the sign of $s_{T}\left(X_{t}\right)$. For the rest of the paper, we will assume that this sign is constant for each bond, although it can change across different times-t-maturity, since the sign of the sensitivity to the risk factor can depend on maturity.

The no-arbitrage condition -if no coupons are paid- implies the following constraint for conditional expected instantaneous bond returns:

$$
m_{T}\left(X_{t}\right)=r_{t}+\lambda\left(X_{t}\right) \frac{B_{T}^{\prime}\left(X_{t}\right)}{B_{T}\left(X_{t}\right)}
$$

where $r_{t}$ is the return on a bond maturing instantaneously and $\lambda\left(X_{t}\right)$ denotes the constant of proportionality across maturities, which can be interpreted as the market price of risk associated with the single risk factor. Substituting (3) into (4),

$$
\frac{m_{T}\left(X_{t}\right)-r_{t}}{s_{T}\left(X_{t}\right)}=\frac{\lambda\left(X_{t}\right)}{\sigma\left(X_{t}\right)}
$$


the relation above simply states that the instantaneous conditional Sharpe ratio should be constant across bond maturities. The idea behind our approach is to exploit this relationship between expected bond returns across maturities.

Suppose that the market risk premium can be consistently estimated from prices of different types of bonds, that is, zero-coupon bonds with different times to maturity. If estimates of $\lambda\left(X_{t}\right) / \sigma\left(X_{t}\right)$ vary significantly across different bond price series, it can be concluded that differences in term premiums across maturities cannot be explained by bonds' exposure to a single risk factor.

To derive the test, we proceed as follows. First, from expressions (3) and (4),

$$
B_{T}\left(X_{t}\right) m_{T}\left(X_{t}\right)=B_{T}\left(X_{t}\right) r_{t}+\lambda\left(X_{t}\right) \frac{s_{T}\left(X_{t}\right) B_{T}\left(X_{t}\right)}{\sigma\left(X_{t}\right)}
$$

Substituting (6) into (2) leads to:

$$
\frac{d B_{T}\left(X_{t}\right)-B_{T}\left(X_{t}\right) r_{t} d t}{B_{T}\left(X_{t}\right)}=\frac{s_{T}\left(X_{t}\right) \lambda\left(X_{t}\right)}{\sigma\left(X_{t}\right)} d t+s_{T}\left(X_{t}\right) d W_{t}
$$

and dividing each side by $s_{T}\left(X_{t}\right)$ :

$$
\frac{d B_{T}\left(X_{t}\right)-B_{T}\left(X_{t}\right) r_{t} d t}{B_{T}\left(X_{t}\right) s_{T}\left(X_{t}\right)}=\frac{\lambda\left(X_{t}\right)}{\sigma\left(X_{t}\right)} d t+d W_{t}
$$

Note that the RHS in equation (7) does not depend on maturity.

Now, for empirical purposes, consider the discrete-time approximation where instantaneous returns are replaced by observable returns $R_{T t+\Delta}=\left(B_{T}\left(X_{t+\Delta}\right)-B_{T}\left(X_{t}\right)\right) / B_{T}\left(X_{t}\right)$ :

$$
\frac{R_{T t+\Delta}-r_{t} \Delta}{s_{T}\left(X_{t}\right)}=\frac{\lambda\left(X_{t}\right)}{\sigma\left(X_{t}\right)} \Delta+\varepsilon_{\Delta t}
$$


For any pair of maturities, say $T_{1} \equiv 1$ and $T_{2} \equiv 2$, if the discrete-time approximation were exact and returns were observable without noise, the following equality would hold under the null hypothesis of a single factor:

$$
Y_{t} \equiv \frac{R_{1(t+1)}-r_{t}}{s_{1}\left(X_{t}\right)}=\frac{R_{2(t+1)}-r_{t}}{s_{2}\left(X_{t}\right)} \equiv Z_{t}
$$

where we have redefined $r_{t}$ and $\frac{\lambda\left(X_{t}\right)}{\sigma\left(X_{t}\right)}$ so $\Delta=1$.

Since zero-coupon bond returns are generally not observable, they must be recovered from some estimate of the (zero coupon bond) yield curve. We thus assume:

$$
\begin{aligned}
Y_{t} & \equiv \frac{R_{1(t+1)}-r_{t}}{s_{1}\left(X_{t}\right)}=\frac{\lambda}{\sigma}\left(X_{t}\right)+\varepsilon_{t}+\eta_{1 t} \\
Z_{t} & \equiv \frac{R_{2(t+1)}-r_{t}}{s_{2}\left(X_{t}\right)}=\frac{\lambda}{\sigma}\left(X_{t}\right)+\varepsilon_{t}+\eta_{2 t}
\end{aligned}
$$

where $\eta_{1 t}$ and $\eta_{2 t}$ are zero-mean errors that can be dependent and serially correlated, but independent of $X_{t}$. The null hypothesis then becomes,

$$
H_{0}: E_{t}\left(Y_{t} \mid X_{t}\right)=E_{t}\left(Z_{t} \mid X_{t}\right)
$$

Under the alternative hypothesis, some structure is expected in the difference so we consider the set of alternatives:

$$
H_{1}: E_{t}\left(Y_{t} \mid X_{t}\right)=E_{t}\left(Z_{t} \mid X_{t}\right)+m_{t}
$$

where $m_{t}=m(t / n)$ and $m(\cdot)$ is a continuous function that captures the time-varying structure due to the presence of other risk factors. Note that this specification does not require stationarity of the variables. 
As it can be seen, we are dealing with the problem of testing for equality of two regression functions. For independent data, this problem has been studied for the fixed design case by Hall and Hart (1990) and Delgado (1993). Cabus (1998) considers the two sample case of random design, again for independent data. Koul and Schick (1997, 2003) and Koul and Stute (1999) propose and study some robust testing for autoregression function modeling in an order-one Markov time series. Finally, in a stationary context, Ferreira and Stute (2003) derive a test based on marked empirical processes. Here, we consider a different statistic in the same context under the null but for a different set of alternatives.

The following Kolmogorov-Smirnov type statistics will be computed for testing purposes:

$$
\begin{aligned}
& z_{1}=\frac{1}{\sqrt{\widehat{a}}} \max _{0 \leq t \leq 1} S_{n}(t) \Longrightarrow_{d} \max _{0 \leq v \leq 1} B(v) \text { to test for } m(\cdot)>0 \\
& z_{2}=\frac{1}{\sqrt{\widehat{a}}} \max _{0 \leq t \leq 1}\left|S_{n}(t)\right| \Longrightarrow_{d} \max _{0 \leq v \leq 1}|B(v)| \text { to test for } m(\cdot) \neq 0
\end{aligned}
$$

where $B(v)$ denotes the standard Brownian motion, $S_{n}(t)=\frac{1}{\sqrt{n}} \sum_{s=1}^{[n t]} D_{s}$, with $D_{s}=Y_{s}-Z_{s}$, and $\widehat{a}=\frac{1}{2 n} \sum_{s=1}^{n-1}\left(D_{s+1}-D_{s}\right)^{2}$. The derivation of the distribution of the statistics is provided in the Appendix.

To apply the test in the present context, we follow the steps described below:

- Compute consistent estimators of $s_{1}\left(X_{t}\right)$ and $s_{2}\left(X_{t}\right)$ under the null hypothesis;

- Construct the series $Y_{t}$ and $Z_{t}$ and the difference $D_{t}$;

- Use a subsample of size $m$ of order $o\left(n^{-4 / 5}\right)$ and compute the statistic $S_{n}(t)$. The use of a subsample is needed in order to avoid an overrejection of the null hypothesis due to estimation error in $s_{1}$ and $s_{2}$, (see e.g. Mammen, 2000 and the Appendix A1); 
- Compute the estimator $\widehat{a}$, and test statistics $z_{1}$ for the one-sided test and $z_{2}$ for the two-sided test;

- Compute the $p$-values $P\left(\max _{0 \leq v \leq 1}|B(v)|>z_{2}\right)$ and $P\left(\max _{0 \leq v \leq 1} B(v)>z_{1}\right)$.

We apply this procedure under two alternative assumptions: (i) the short rate is perfectly correlated with the single factor; and (2) the risk factor is not perfectly correlated with the short rate. As mentioned in the introduction, an example of a case where the risk factor does not identify with the risk factor is the class of quadratic term structure models. In such models, the instantaneous rate is a quadratic function of the unobservable risk factor, so it is not perfectly correlated with it. Moreover, in single factor quadratic models, the state of the system may be determined by observing the short rate and the term spread. See for instance Longstaff (1989) for the single factor case or Ahn et al. (2002) for a multi-factor generalization.

If the short rate perfectly identifies with the risk factor, its value at any point in time fully characterizes the state of the system. Estimators of diffusion coefficients $\widehat{s}_{1}$ and $\widehat{s}_{2}$ are obtained as:

$$
\begin{aligned}
& \widehat{s}_{1}^{2}\left(r_{t}\right)=\operatorname{Var}\left(R_{1(t+1)} \mid r_{t}\right)=E\left(R_{1(t+1)}^{2} \mid r_{t}\right)-E\left(R_{1(t+1)} \mid r_{t}\right)^{2} \\
& \widehat{s}_{2}^{2}\left(r_{t}\right)=\operatorname{Var}\left(R_{2(t+1)} \mid r_{t}\right)=E\left(R_{2(t+1)}^{2} \mid r_{t}\right)-E\left(R_{2(t+1)} \mid r_{t}\right)^{2}
\end{aligned}
$$

For the practical computation of these expected values we use a general smoother, similarly to Stanton (1997),

$$
\widehat{E}_{t}(\cdot \mid r)=\frac{\sum_{t=1}^{T-1} W_{t}(r)}{\sum_{t=1}^{T-1} W_{t}(r)}
$$


where, instead of a usual kernel, the weights are defined as,

$$
W_{t}(r)=K\left(\frac{F_{1 n}(r)-F_{1 n}\left(r_{t}\right)}{h}\right)
$$

where $F_{1 n}$ is the empirical distribution of the short rate and $K$ a function kernel of order 2 (see e.g. Härdle (1990) for details on smoothing estimators). This type of estimator is known as Symmetrized Nearest Neighbors (SNN) and belongs to the class of nonparametric estimators. We propose the use of SNN because they present a better performance than the kernels for non-uniformly distributed data, as is the case for the short rate. (Ferreira et al. (2003) present a detailed study of the properties of the SNN estimators in financial applications). Roughly speaking, SNN are equivalent to kernels where the smoothing parameter varies; it increases where the density of the design is low and decreases where it is large. This is a desirable property that improves the estimation process in the tails; that is, for extreme values of the short rate.

On the other hand, when the risk factor does not identify with the short rate, because there still is a single source of risk, instantaneous returns are perfectly correlated and no-arbitrage implies that (7) must hold for any bond. Since the current level of the short term interest rate does not fully determine the value of the state variable, however, we assume that the state of the system conditional on $X_{t}$ can be expressed equivalently in terms of the short rate and the slope of the yield curve, proxied by the spread between the long rate and the short rate. Ahn et al. (2002) have shown for instance that for single-factor quadratic term structure models, yields of any maturity are quadratic in the single risk factor. It can further be shown that the state of the system can be inverted in terms of the short rate and the spread, which provides a motivation for our approach.

Under this assumption, $s_{T}\left(X_{t}\right)$ can be identified as $s_{T}(r(t), s p(t))$, so a consistent estimation of 
$s_{T}$ can be obtained conditional on the short rate and the slope on the yield curve:

$$
\widehat{s}_{T}^{2}\left(r_{t}, s p_{t}\right)=\operatorname{Var}\left(R_{T(t+1)} \mid r_{t}, s p_{t}\right)=E\left(R_{T(t+1)}^{2} \mid r_{t}, s p_{t}\right)-E\left(R_{T(t+1)} \mid r_{t}, s p_{t}\right)^{2}
$$

A consistent estimator of the expected values is obtained through the bivariate SNN estimator, defined as:

$$
\widehat{E}_{t}(\cdot \mid r, s p)=\frac{\sum_{t=1}^{T-1} W_{t}(r, s p)}{\sum_{t=1}^{T-1} W_{t}(r, s p)},
$$

with

$$
W_{t}(r, s p)=K\left(\frac{F_{1 n}(r)-F_{1 n}\left(r_{t}\right)}{h_{r}}\right) K\left(\frac{F_{2 n}(s p)-F_{2 n}\left(s p_{t}\right)}{h_{s p}}\right)
$$

where $K$ is again a kernel of order 2 , and $F_{1 n}$ and $F_{2 n}$ denote the empirical distribution of the short rate and the spread term respectively.

It is interesting to remark that the stationarity of the short rate and the spread allows us to ensure the consistency of the diffusion estimator. In order to obtain a consistent estimator in a nonstationary setting, the estimator proposed in Bandi and Philips (2003) could be used. Instead of stationarity, the authors require "the continuous trajectory of the process to visit any level in its range an infinity number of times over time". In either case, the test applies.

\section{Finite sample properties}

In this section, we use Monte Carlo simulations to explore the properties of the test in finite samples. Although such controlled experiments are always necessary, the analysis is particularly interesting in this specific context for two reasons. First, it will enable us to evaluate the accuracy of the 
discrete-time approximation (8) for any desired frequency of data. Second, it will also enable us to assess whether the use of $\hat{s}_{T}$ instead of $s_{T}$ affects the properties of the test in finite samples.

\section{$2.1 \quad$ Size}

In order to analyze the size of the test, we first simulate interest rate data and bond returns from a single-factor affine term structure model. More specifically, we choose the single-factor version of the Cox-Ingersoll-Ross (CIR) (1985a, 1985b) model using parameter estimates from Geyer and Pichler (1999). In the one-factor CIR model, the instantaneous nominal interest rate equals the unobservable risk factor, which is assumed to be generated by a square-root diffusion. Assuming a linear risk premium, closed-form solutions for prices of default-free bonds of any maturity are readily available (see Appendix). We proceed as follows:

1. We draw realizations from the risk factor diffusion, using the Euler (first-order) approximation, with a step length of $1 / 1000$ th of a year (40 realizations per day), and then use price formulas to obtain bond prices for maturities equal to 6 months, 1 year, 5 years and 10 years (as well as 6 months, 1 year, 5 years and 10 years minus one day);

2. We drop all but daily observations and compute daily returns from buying a bond at day $t$, and selling it one day later;

3. We use bond returns to compute returns in excess of the instantaneous rate and we estimate nonparametrically bond return conditional volatilities;

4. We divide each excess return by its conditional volatility and then add to each series a zeromean iid measurement error with standard deviation ${ }^{2}$ equal to 0.005 .

5. We apply the tests to pairs of series corresponding to two bonds of different maturities. 
6. We repeat steps 1-5, 1,000 times.

As shown in the Appendix (Table A1), for 10 years of daily data, empirical sizes for the twosided test resemble nominal sizes under the null hypothesis, while the one-sided test displays some tendency towards underrejection. As expected for this model, estimating the diffusion by conditioning on both the short rate and the term spread, does not affect the empirical size of the test. Finally note that the discretization bias resulting from the use of daily returns does not lead to overrejection of the null hypothesis.

Next, we explore the performance of the test when the affine assumption is removed. In order to do so, we use the squared-autoregressive-independent-variable nominal term structure (SAINTS) model of Constantinides (1992), where the instantaneous interest rate is a quadratic function of the single unobservable risk factor. Consequently, in this model, the instantaneous rate is only sufficient for determining bond prices when the risk factor does not change sign. Otherwise, two different values of the risk factor can correspond to the same value of the short rate. This justifies the need for conditioning on extra information from the term structure. In our simulations, we have employed parameter estimates for the SAINTS model from Lu (2000). The model specification, pricing formulas, and parameter values are given in the Appendix. Table A2 displays simulation results, which suggest that the empirical size is robust to the true one-factor model class belonging to the quadratic family. Rejection rates are similar both when conditioning on the short rate exclusively and when conditioning on the short rate and the term spread. This, however, is not surprising, since for this specific parameter choice the unobservable risk factor seldom changes sign. 


\subsection{Power}

We have chosen the two-factor CIR model, along with parameter estimates from Geyer and Pichler (1999), in order to evaluate the power of the test to reject the single-factor hypothesis.

We use daily returns and set the number of years equal to 10 (Table A3). Both the one-sided and the two-sided tests reject almost $100 \%$ of the times the null hypothesis of a single priced risk factor, when risk-adjusted 10-year bond excess returns are compared to other series. When the 5year bond is compared to the 1-year bond and the 6-month bond, however, rejection rates (for both significance levels) fall below $50 \%$ for the one-sided test and $30 \%$ for the two-sided test. Finally, the test lacks all power to reject the null when the 1-year bond is compared to the 6-month bond. Conditioning on the spread does not alter these conclusions.

Increasing the amount of available data to 30 years (Table A4) results in more reasonable rejection rates when the 5-year bond is compared to bonds of shorter maturity. When 1-year and 6-month bonds are compared, however, there is no appreciable improvement in the power of the test. Again, conditioning on the term spread leads to similar conclusions. Simulation results therefore suggest that sample size and, especially, the choice of bond maturities have a considerable impact on the power of the test to reject the null hypothesis.

Finally, changes in parameter values also affect the power of the test to reject the null. Since the null hypothesis is rejected because bonds are exposed to a second factor of risk, increasing the amount of risk associated with the second risk factors should increase the power of the test. To see this, we increase the value of the diffusion coefficient in the Ito process driving the second risk factor dynamics. As Table A5 shows, both the one-sided and the two-sided test reject the null hypothesis most of the time, with a single exception: the 6-month/1-year maturity comparison. 


\section{Data and results}

In this section, we apply the test to bond data from two different public debt markets: Spain and the United States. In both cases, the zero yield curve enables us to recover zero-coupon bond prices and their associated returns. We then estimate the diffusion function for each maturity and construct the series $Y_{t}$ and $Z_{t}$. Finally, test statistics (9) and (10) are computed for all pairs of bonds.

\subsection{Construction of the dataset}

\subsubsection{Spanish Market}

The dataset consists of 2,249 daily observations of the term structure of interest rates covering the full January 1993 to December 2001 nine-year period. The yield curve has been fitted to data on fixed-income assets issued by the Spanish Treasury, following an exponential spline approach as in Vasicek and Fong (1982), which takes into account both coupon payments and tax effects. The evolution of the yield curve over time is shown in Figure 1. In order to compute daily bond returns, yields-to-maturity on three-month, one-year, five-year, and ten-year treasuries as well as yields with the same terms to maturity minus one day, were first converted into prices. Table 1a presents a description of the means and standard deviations of bond daily returns for the whole sample. Returns on the 5-year bond, for instance, correspond to a strategy of buying every day a zero-coupon bond maturing in five years and selling it on the following day.

The short rate was proxied by the (continuously compounded) one-month $\operatorname{rate}^{3}, r(t)$, and the slope of the yield curve was proxied by the spread between the 10-year yield and the one-month

rate, $s p(t)$. Figure 2 shows the historical evolution of the term spread. Nonparametrically estimated 
bond diffusion functions when conditioning on the short rate only, are displayed on Figure 5.

\subsubsection{U.S. Market}

The dataset consists of 5,350 daily observations of the term structure of interest rates covering the period from April 1982 to May 2003. More specifically, we use Treasury yield curve rates, commonly referred to as "Constant Maturity Treasury" rates, as proxies for interest rates of different maturities. These rates are interpolated by the Treasury from the yield curve, which is estimated on a daily basis using a cubic spline model and employs closing market bid yields on actively traded Treasury securities in the over-the-counter market ${ }^{4}$. Yields are displayed on Figure 3.

To construct the series of conditional mean returns per unit risk, we first recover prices from yields, and then compute one-period returns from buying six-month, one-year, five-year and tenyear zero-coupon bonds and selling them one day later. Table $1 \mathrm{~b}$ presents a description of the annualized means and deviations of bond daily returns for the whole sample. Given the available data, the short rate was proxied in this case by the (continuously compounded) 3-month rate, $r(t)$, and the slope of the yield curve was proxied by the spread between the 10-year yield and the 3-month rate, $s p(t)$. Figure 4 shows the term spread series. Nonparametrically estimated bond diffusions as functions of the short rate are displayed on Figure 6.

\subsection{Results}

\subsubsection{Spanish market}

Test results for Spain are displayed on Tables 2 and 3. For both cases considered (the short rate as the state variable and the short rate and the spread jointly capturing the state of the system) and all pairs of maturities, the null hypothesis of equal expected excess returns per unit risk cannot be 
rejected. Note that this conclusion cannot be attributed to any particular parametrization of the state variable dynamics under the true or the risk neutral probability measure. It does however rely on the assumption that our estimates are consistent and that the one-month rate and the spread between the 10-year yield and the one-month yield summarize all relevant information about the state of the system.

Just as happens with other samples, Spanish interest rates of different maturities have been found to be driven by at least three common factors. In light of this evidence, our finding suggests that risk premiums embedded in bond returns are dominated by exposure to a single factor. If present, additional risk factors are statistically difficult to detect through their effect on investor compensation. The main implication is that a sufficiently flexible time-homogenous single-factor term structure model can explain well the observed cross section of bond returns and its dynamics over time.

\subsubsection{U.S. market}

Test results for the U.S. are displayed on Tables 4 and 5 . For both cases considered, bond premiums per unit risk are not significantly different across maturities. Considering shorter maturities results in (statistically not significant) higher estimates of the market price of risk per unit risk despite the favorable liquidity features enjoyed by Treasury bill holders in the U.S. In fact, the null hypothesis that the risk premium over the bond's diffusion is equal for ten-year and one-year treasuries is rejected at the $10 \%$ significance level against the alternative hypothesis that the normalized risk premium is higher for the one-year bond.

In order to analyze the robustness of these results to different data, we have replaced threemonth and six-month rates obtained from the fitted yield curve, with true Treasury Bill rate 
data. This enables us to extend all our series since secondary market T-Bill data (an average of dealer quotes from the secondary market) are available from February 1962. Tables 6 and 7 report test statistics applied to the extended dataset. Although the sample now consists of 10,531 daily observations, corresponding to 42 years, test results are very similar to those of Tables 4 and 5 : the single priced risk factor hypothesis cannot be rejected for the U.S. post-war period.

\section{Summary and conclusions}

In this paper, we have proposed a new method to test for the hypothesis that a single priced risk factor drives the evolution of the yield curve over time. Our approach extends the previous literature on the empirical performance of term-structure models in that results do not depend on any particular parametric specification of the state variable dynamics, the form of the market price of risk, or the relationship between the single state variable and the short term interest rate. It simply exploits the observation that in the presence of a single priced source of uncertainty, instantaneous returns are conditionally perfectly correlated across maturities, so for no arbitrage opportunities to exist, each asset's instantaneous risk premium must be proportional to its exposure to uncertainty. Provided conditional volatility can be consistently estimated and in presence of zeromean measurement errors, expected differences across maturities between excess returns over their estimated conditional volatility should be statistically not significantly from zero. We develop a formal testing method that measures the statistical significance of differences in conditional means for series of excess returns per unit risk. As compared to other available tests, ours does not require a fixed design and does not assume independent variables.

The test cannot reject the single factor hypothesis for the Spanish and U.S. Government bond 
markets. Results can be interpreted as evidence in favor of the multifactor hypothesis when no parametric constraints are imposed on the dynamic term structure model. Although a Monte Carlo analysis suggests that the test lacks power to reject the null when comparing returns of short term bonds, the test has good power when short and long term bond returns are compared, a result that remains when considering different parameters in the simulation study ${ }^{5}$.

As for possible extensions to this work, an alternative approach could be based on a conditional version of the Generalized Method of Moments, (see Brandt, 1999). Indeed, a nonparametric estimator of the normalized market price of risk could be obtained at each point in time from the set of moment restrictions imposed by the no arbitrage assumption on bond returns across maturities. The main advantage of this approach is its potential to incorporate information on multiple bonds, which should result in more power to reject the null. Naturally, the properties of such an estimator would have to be derived in this specific context. The biggest challenge, however, would be that of constructing a test statistic for the null hypothesis that the model is true for all $t$. We leave this promising line of research for future work. 


\section{Appendix}

\section{A1. Derivation of the test.}

Consider two samples generated from the two following generating processes, where for simplicity $t$ denotes directly the rescaled time index in $(0,1)$.

$$
\begin{aligned}
Y_{t} & =E\left(Y_{t} \mid X_{t}\right)+\sigma_{1}(t) \varepsilon_{1 t} \\
Z_{t} & =E\left(Z_{t} \mid X_{t}\right)+\sigma_{2}(t) \varepsilon_{2 t}
\end{aligned}
$$

Let $\sigma_{1}(\cdot), \sigma_{2}(\cdot)$ be continuous unknown functions, with one bounded derivative in the $(0,1)$ interval. The errors $\varepsilon_{1 t}$ and $\varepsilon_{2 t}$ are serially independent with zero mean, and variance equal to one, and they can be correlated with correlation function denoted by $\rho(\cdot)$.

The interest is to test for the null hypothesis $H_{0}: E\left(Y_{t} \mid X_{t}\right)=E\left(Z_{t} \mid X_{t}\right)$ against the two-sided alternative $H_{1}: E\left(Y_{t} \mid X_{t}\right) \neq E\left(Z_{t} \mid X_{t}\right)$ or the one-sided alternative $H_{1}: E\left(Y_{t} \mid X_{t}\right)>E\left(Z_{t} \mid X_{t}\right)$

For each sample size $n$, we assume that the observations are taken at equidistance points and define $D_{i}=Y_{i}-Z_{i}$. Let us analyze the partial sums process, defined in the unit interval $(0,1)$ by

$$
S_{n}(t)=\frac{1}{\sqrt{n}} \sum_{i=1}^{[n t]} D_{i}
$$

Under the null, $S_{n}(t)$ converges in law to $\left(\Longrightarrow_{d}\right) B(T(t))$, where $B$ denotes a Brownian motion and $T(t)=\int_{0}^{t} \varphi(u) d u$, where $\varphi(u)=\sigma_{1}^{2}(u)+\sigma_{2}^{2}(u)+2 \rho(t) \sigma_{1}(u) \sigma_{2}(u)$.

To proof this result write $n^{-1 / 2} \sum_{i=1}^{[n t]} D_{i}=n^{-1 / 2} \sum_{i=1}^{[n t]}\left(\sigma_{1}\left(t_{i}\right) \varepsilon_{1 i}-\sigma_{2}\left(t_{i}\right) \varepsilon_{2 i}\right)$.

For each $t$ consider the map $u=T(t) . T(t)$ is a continuous, monotone nondecreasing function, and therefore, there is a well defined inverse $t=T^{-1}(u)$. 
For each $u$, we can write the partial sums as $S_{u}=\frac{1}{\sqrt{n}} \sum_{i=1}^{\left[n T^{-1}(u)\right]} D_{i}$. It holds that $E\left(S_{u}\right)=0$ and $V\left(S_{u}\right)=\frac{1}{n} \sum_{i=1}^{\left[n T^{-1}(u)\right]}\left[\varphi\left(T^{-1}\left(u_{i}\right)\right)\right] \rightarrow \int_{0}^{T^{-1}(u)} \varphi\left(T^{-1}(v)\right) d v=\int_{0}^{T^{-1}(u)} \varphi\left(T^{-1}(v)\right) d v=T \circ T^{-1}(u)=$ $u$

Hence, directly from Donsker's theorem (see e.g. Billingsley, 1968), we have that $S_{u} \Longrightarrow_{d} B(u)$, which written in terms of $t$, leads to the result.

Now, consider the set of alternatives $E\left(Y_{t} \mid X_{t}\right)-E\left(Z_{t} \mid X_{t}\right)=m(t)$. To check for the consistency of the test, define the process

$$
\begin{aligned}
n^{-1} \sum_{i=1}^{[n t]} D_{i} & =n^{-1} \sum_{i=1}^{[n t]}\left(m\left(t_{i}\right)+\sigma_{1}\left(t_{i}\right) \varepsilon_{1 i}-\sigma_{2}\left(t_{i}\right) \varepsilon_{2 i}\right) \rightarrow \\
I(t) & =\int_{0}^{t} m(u) d u \text { a s. }
\end{aligned}
$$

Therefore, the process $S_{n}(t)$ diverges to infinity whenever we consider global alternatives where $m(\cdot) \neq 0$, since $I(t)=0 \Leftrightarrow m(\cdot)=0$. For local alternatives of the form $E\left(Y_{t} \mid X_{t}\right)-E\left(Z_{t} \mid X_{t}\right)=$ $n^{-1 / 2} m(\cdot)$

$$
S_{t} \Longrightarrow_{d} B(T(t))+\int_{0}^{t} m(u) d u \neq B(T(t)) .
$$

To test for the one-sided alternative $m(t)>0$, an application of the functional limit theorem shows that the K-S statistic defined as $\max _{0 \leq t \leq 1} S_{n}(t)$ has the limit

$$
\max _{0 \leq t \leq 1} S_{n}(t) \Longrightarrow \max _{0 \leq t \leq 1} B \circ T(t)=\max _{0 \leq u \leq T(1)=a} B(u)=\max _{0 \leq v \leq 1} B(v a)={ }_{d} \sqrt{a} \max _{0 \leq v \leq 1} B(v)
$$

For the two-sided alternative $m(t) \neq 0$, we use the analogous result

$$
\max _{0 \leq t \leq 1}\left|S_{n}(t)\right| \Longrightarrow_{d} \sqrt{a} \max _{0 \leq v \leq 1}|B(v)|
$$

As the estimator of $a=T(1)$, we use the one proposed in Hall and Hart (1990), $\widehat{a}=$ $\frac{1}{2 n} \sum_{i=1}^{n-1}\left(D_{i+1}-D_{i}\right)^{2}$, which is consistent under the null and the alternative hypothesis. 
To apply the one-sided test we use the well known result coming from the reflection principal,

$$
P\left[\max _{0 \leq v \leq 1} B(v) \leq \delta\right]=1-2 \Phi(\delta)
$$

and, for the two-sided case, the distribution of $\max _{0 \leq v \leq 1}|B(v)|$ can be easily tabulated.

Hence, the final statistics are

$$
\begin{aligned}
& z_{1}=\frac{1}{\sqrt{\widehat{a}}} \max _{0 \leq t \leq 1} S_{n}(t) \Longrightarrow_{d} \max _{0 \leq v \leq 1} B(v) \text { to test for } m(\cdot)>0 \\
& z_{2}=\frac{1}{\sqrt{\widehat{a}}} \max _{0 \leq t \leq 1}\left|S_{n}(t)\right| \Longrightarrow_{d} \max _{0 \leq v \leq 1}|B(v)| \text { to test for } m(\cdot) \neq 0
\end{aligned}
$$

Second, we account for the fact that we do not observe directly $Y_{i}$ and $Z_{i}$, the test in practice is based on

$$
\begin{aligned}
\widehat{D}_{i} & =\widehat{Y}_{i}-\widehat{Z}_{i}=Y_{i} \frac{s_{1 i}}{\widehat{s}_{1 i}}-Z_{i} \frac{s_{2 i}}{\widehat{s}_{2 i}} \\
& =D_{i}+Y_{i}\left(\frac{s_{1 i}}{\widehat{s}_{1 i}}-1\right)-Z_{i}\left(\frac{s_{2 i}}{\widehat{s}_{2 i}}-1\right)
\end{aligned}
$$

Therefore,

$$
\begin{aligned}
\widehat{S}_{n}(t) & =\frac{1}{\sqrt{n}} \sum_{i=1}^{[n t]} \widehat{D}_{i} \\
& =\frac{1}{\sqrt{n}} \sum_{i=1}^{[n t]} D_{i}+\alpha_{n}(t) \\
& =S_{n}(t)+\alpha_{n}(t) \\
& \text { where } \\
\alpha_{n}(t) & =\frac{1}{\sqrt{n}} \sum_{i=1}^{[n t]}\left[Y_{i}\left(\frac{s_{1 i}}{\widehat{s}_{1 i}}-1\right)-Z_{i}\left(\frac{s_{2 i}}{\widehat{s}_{2 i}}-1\right)\right]
\end{aligned}
$$


The terms $\left(s_{1 i} / \widehat{s}_{1 i}-1\right)$ are clearly dependent and, due to the nonparametric estimation properties, have variance of order $o\left(n^{-4 / 5}\right)$, so the process $\alpha_{n}(t)$ is not negligible if we use the same sample size for estimation purpose and for the test. To overcome the consideration of the nontrivial limit distribution of $\alpha_{n}(t)$, we propose to consider a smaller sample size $m$ to develope the test. That is, we compute $\widehat{S}_{m}(t)$ with leading term $S_{m}(t)$. For that, it is enough to select the subsample $m$ of order $o\left(n^{-4 / 5}\right)$. Doing this, the process

$$
\begin{aligned}
\alpha_{m}(t)= & \frac{1}{\sqrt{m}} \sum_{i=1}^{[m t]}\left[Y_{i}\left(\frac{s_{1 i}}{\widehat{s}_{1 i}}-1\right)-Z_{i}\left(\frac{s_{2 i}}{\widehat{s}_{2 i}}-1\right)\right] \rightarrow 0 \\
& \text { since } \\
\mathbb{E}\left(\alpha_{m}(t)\right) \rightarrow & 0 \\
& \text { and } \\
\mathbb{V}\left(\alpha_{m}(t)\right)= & O\left(m^{-1} \cdot m^{2} \cdot n^{-4 / 5}\right) \\
= & o(1)
\end{aligned}
$$

and the process defined by $\alpha_{m}(t)$ is now negligible with respect to $S_{m}(t)$. 


\section{A2. A simulation study}

In this section, we describe the CIR model in its multi-factor version. We then describe the squared-autoregressive-independent-variable nominal term structure (SAINTS) model of Constantinides (1992). In both cases, we provide the parameter values employed in our simulations.

\section{CIR (Cox-Ingersoll-Ross, 1985a, 1985b)}

In the $K$-factor CIR model, risk factors or state variables are assumed to follow independent square-root diffusions:

$$
d x_{t, j}=\kappa_{j}\left(\theta_{j}-x_{t, j}\right) d t+\sigma_{j} \sqrt{x_{t, j}} d W_{t, j} \quad(j=1, \cdots, K),
$$

and the instantaneous rate is the sum of $K$ risk factors or state variables,

$$
r_{t}=\sum_{j=1}^{K} x_{t, j}
$$

Under the model assumptions, bond risk premiums are affine in the state variables with associated constants $\lambda_{j}, \quad j=1, \cdots, K$. The price at $t$ of a zero coupon bond maturing at time $T$ can then be shown to be exponential affine in the risk factors:

$$
B_{T}\left(x_{t, 1}, x_{t, 2}, \cdots, x_{t, K}\right)=\prod_{j=1}^{K} A_{j}(T-t) \exp \left(-\sum_{j=1}^{K} B_{j}(T-t) x_{t, j}\right)
$$

where 


$$
\begin{aligned}
A_{j}(\tau) & =\left(\frac{2 \phi_{j, 1} \exp \left(\phi_{j, 2} \tau / 2\right)}{\phi_{j, 4}}\right)^{\phi_{j, 3}} \\
B_{j}(\tau) & =\frac{2\left(\exp \left(\phi_{j, 1} \tau\right)-1\right)}{\phi_{j, 4}} \\
\phi_{j, 1} & =\sqrt{\left(\kappa_{j}+\lambda_{j}\right)^{2}+2 \sigma_{j}^{2}} \\
\phi_{j, 2} & =\kappa_{j}+\lambda_{j}+\phi_{j, 1} \\
\phi_{j, 3} & =2 \kappa_{j} \theta_{j} / \sigma_{j}^{2} \\
\phi_{j, 4} & =2 \phi_{j, 1}+\phi_{j, 2}\left(\exp \left(\phi_{j, 1} \tau\right)-1\right)
\end{aligned}
$$

where $-\lambda_{j}$ represents the market price of risk associated with the $j$ th factor.

In our simulations, we use parameter values from Geyer and Pichler (1999), who have employed a state-space approach to estimate the model parameters for $K=1, \cdots, 5$. In particular, for the onefactor model, and U.S. interest rate data in 1964-1993 period, they obtain the following estimates: $\kappa_{1}=0.169, \sigma_{1}=0.321, \lambda_{1}=-0.201, \theta_{1}=6.56$. For the two-factor model, they find $\kappa_{1}=0.0718$, $\sigma_{1}=0.216, \lambda_{1}=-0.213, \theta_{1}=4.3, \kappa_{2}=0.783, \sigma_{2}=1.22, \lambda_{2}=-0.914, \theta_{2}=1.64$.

\section{SAINTS (Constantinides, 1992)}

In our presentation of the model, we follow Lu's (2000) parametrization. State variables are assumed to follow mean-reverting diffusions:

$$
d x_{t, j}=\kappa_{j}\left(\theta_{j}-x_{t, j}\right) d t+\sigma_{j} d W_{t, j} \quad(j=1, \cdots, K)
$$

where $W_{t, j}$ are independet Wiener processes. It turns out that under the model assumptions, both the instantaneous interest rate and yields on bonds of all maturities are quadratic functions of the state variables: 


$$
r_{t}=g-\sum_{j=1}^{K}\left[\sigma_{j}^{2}+2 \kappa_{j} \theta_{j} x_{t, j}-2\left(\kappa_{j}-\sigma_{j}^{2}\right) x_{t, j}^{2}\right]
$$

The price of zero coupon maturing at $T=t+\tau$ periods is given by:

$$
\begin{aligned}
B_{T}\left(x_{t, 1}, x_{t, 2}, \cdots, x_{t, K}\right)= & \left(\prod_{j=1}^{K} H_{j \tau}\right)^{-\frac{1}{2}} \exp \left[\sum_{j=1}^{K}\left(\kappa_{j}-g\right) \tau\right. \\
& \left.-\sum_{j=1}^{K} \frac{\left(H_{j \tau}-1\right) x_{t, j}^{2}-2 \theta_{j}\left(e^{\kappa_{j} \tau}-1\right) x_{t, j}-\theta_{j}^{2}\left(e^{\kappa_{j} \tau}-1\right)^{2}}{H_{j \tau}}\right]
\end{aligned}
$$

where

$$
H_{j \tau}=\frac{\sigma_{j}^{2}}{\kappa_{j}}+\left(1-\frac{\sigma_{j}^{2}}{\kappa_{j}}\right) e^{2 \kappa_{j} \tau}
$$

For the one-factor model and U.S. interest rate data (1952-1995), Lu (2000) reports the following parameter estimates: $g=0.0830, \kappa_{1}=0.0799, \sigma_{1}=0.1178, \theta_{1}=-1.1951$

Below, we report simulation results. Each table reports rejection rates in percent points. 
Table A1 (Size)

One-factor CIR model. 10 years of daily data.

Panel A: Conditioning variable $=$ short rate

\begin{tabular}{|c|c|c|c|c|c|}
\hline \multirow[b]{2}{*}{$Y_{t}$} & \multirow[b]{2}{*}{$Z_{t}$} & \multicolumn{2}{|c|}{ One-sided Test } & \multicolumn{2}{|c|}{ Two-sided Test } \\
\hline & & $\alpha=10 \%$ & $\alpha=5 \%$ & $\alpha=10 \%$ & $\alpha=5 \%$ \\
\hline 10 year & 6 month & 6.4 & 2.9 & 10.0 & 6.6 \\
\hline 10 year & 1 year & 5.9 & 2.6 & 7.5 & 4.5 \\
\hline 10 year & 5 year & 10.3 & 4.9 & 9.4 & 4.9 \\
\hline 5 year & 6 month & 7.0 & 2.5 & 10.0 & 6.6 \\
\hline 5 year & 1 year & 7.2 & 2.9 & 7.8 & 4.7 \\
\hline 1 year & 6 month & 8.4 & 3.6 & 8.6 & 4.6 \\
\hline
\end{tabular}

Panel B: Conditioning variables $=$ short rate, term spread

\begin{tabular}{|cc|cc|cc|}
\hline & & \multicolumn{2}{|c|}{ One-sided Test } & \multicolumn{2}{c|}{ Two-sided Test } \\
$Y_{t}$ & $Z_{t}$ & $\alpha=10 \%$ & $\alpha=5 \%$ & $\alpha=10 \%$ & $\alpha=5 \%$ \\
\hline 10 year & 6 month & 7.0 & 2.6 & 8.8 & 5.5 \\
10 year & 1 year & 8.2 & 3.8 & 9.3 & 5.2 \\
10 year & 5 year & 9.1 & 4.2 & 8.3 & 5.2 \\
5 year & 6 month & 7.4 & 3.5 & 10.4 & 6.2 \\
5 year & 1 year & 8.1 & 4.2 & 9.7 & 5.0 \\
1 year & 6 month & 6.7 & 3.4 & 8.9 & 5.5 \\
\hline
\end{tabular}


Table A2 (Size)

One-factor SAINTS model. 10 years of daily data.

Panel A: Conditioning variable $=$ short rate

\begin{tabular}{|cc|cc|cc|}
\hline & & \multicolumn{2}{|c|}{ One-sided Test } & \multicolumn{2}{c|}{ Two-sided Test } \\
$Y_{t}$ & $Z_{t}$ & $\alpha=10 \%$ & $\alpha=5 \%$ & $\alpha=10 \%$ & $\alpha=5 \%$ \\
\hline 10 year & 6 month & 9.2 & 4.4 & 9.1 & 5.4 \\
10 year & 1 year & 10.1 & 5.2 & 8.7 & 5.1 \\
10 year & 5 year & 8.7 & 4.1 & 7.0 & 3.9 \\
5 year & 6 month & 9.7 & 5.5 & 10.4 & 5.9 \\
5 year & 1 year & 10.9 & 6.3 & 11.5 & 6.4 \\
1 year & 6 month & 10.0 & 4.8 & 9.5 & 5.4 \\
\hline
\end{tabular}

Panel B: Conditioning variables $=$ short rate, term spread

\begin{tabular}{|cc|cc|cc|}
\hline & & \multicolumn{2}{|c|}{ One-sided Test } & \multicolumn{2}{c|}{ Two-sided Test } \\
$Y_{t}$ & $Z_{t}$ & $\alpha=10 \%$ & $\alpha=5 \%$ & $\alpha=10 \%$ & $\alpha=5 \%$ \\
\hline 10 year & 6 month & 8.6 & 4.2 & 8.9 & 5.4 \\
10 year & 1 year & 8.4 & 4.4 & 8.7 & 4.3 \\
10 year & 5 year & 9.1 & 4.8 & 8.5 & 5.0 \\
5 year & 6 month & 8.6 & 4.1 & 8.2 & 4.7 \\
5 year & 1 year & 9.0 & 4.4 & 8.6 & 4.5 \\
1 year & 6 month & 8.8 & 4.3 & 7.9 & 4.5 \\
\hline
\end{tabular}


Table A3 (Power)

Two-factor CIR model. 10 years of daily data.

$$
\left(\sigma_{2}=1.22\right)
$$

Panel A: Conditioning variable $=$ short rate

\begin{tabular}{|cc|cc|cc|}
\hline & & \multicolumn{2}{|c|}{ One-sided Test } & \multicolumn{2}{c|}{ Two-sided Test } \\
$Y_{t}$ & $Z_{t}$ & $\alpha=10 \%$ & $\alpha=5 \%$ & $\alpha=10 \%$ & $\alpha=5 \%$ \\
\hline 10 year & 6 month & 99.0 & 98.0 & 97.7 & 95.1 \\
10 year & 1 year & 99.5 & 98.5 & 98.2 & 96.5 \\
10 year & 5 year & 97.8 & 94.6 & 93.7 & 89.4 \\
5 year & 6 month & 42.5 & 28.6 & 27.6 & 18.4 \\
5 year & 1 year & 44.2 & 30.6 & 29.5 & 20.5 \\
1 year & 6 month & 8.9 & 4.7 & 8.4 & 3.4 \\
\hline
\end{tabular}

Panel B: Conditioning variables $=$ short rate, term spread

\begin{tabular}{|cc|cc|cc|}
\hline & & \multicolumn{2}{|c|}{ One-sided Test } & \multicolumn{2}{c|}{ Two-sided Test } \\
$Y_{t}$ & $Z_{t}$ & $\alpha=10 \%$ & $\alpha=5 \%$ & $\alpha=10 \%$ & $\alpha=5 \%$ \\
\hline 10 year & 6 month & 99.6 & 98.0 & 97.7 & 95.3 \\
10 year & 1 year & 99.2 & 98.3 & 98.0 & 96.4 \\
10 year & 5 year & 98.3 & 95.6 & 95.1 & 91.7 \\
5 year & 6 month & 44.2 & 29.4 & 27.6 & 19.4 \\
5 year & 1 year & 43.2 & 29.6 & 28.3 & 21.3 \\
1 year & 6 month & 10.2 & 5.4 & 10.5 & 5.7 \\
\hline
\end{tabular}


Table A4 (Power)

Two-factor CIR model. 30 years of daily data.

$$
\left(\sigma_{2}=1.22\right)
$$

Panel A: Conditioning variable $=$ short rate

\begin{tabular}{|cc|cc|cc|}
\hline & & \multicolumn{2}{|c|}{ One-sided Test } & \multicolumn{2}{c|}{ Two-sided Test } \\
$Y_{t}$ & $Z_{t}$ & $\alpha=10 \%$ & $\alpha=5 \%$ & $\alpha=10 \%$ & $\alpha=5 \%$ \\
\hline 10 year & 6 month & 100.0 & 100.0 & 100.0 & 100.0 \\
10 year & 1 year & 100.0 & 100.0 & 100.0 & 100.0 \\
10 year & 5 year & 100.0 & 100.0 & 100.0 & 100.0 \\
5 year & 6 month & 74.3 & 61.3 & 60.4 & 50.4 \\
5 year & 1 year & 76.5 & 65.1 & 63.4 & 54.0 \\
1 year & 6 month & 8.6 & 4.6 & 11.2 & 6.2 \\
\hline
\end{tabular}

Panel B: Conditioning variables $=$ short rate, term spread

\begin{tabular}{|cc|cc|cc|}
\hline & & \multicolumn{2}{|c|}{ One-sided Test } & \multicolumn{2}{c|}{ Two-sided Test } \\
$Y_{t}$ & $Z_{t}$ & $\alpha=10 \%$ & $\alpha=5 \%$ & $\alpha=10 \%$ & $\alpha=5 \%$ \\
\hline 10 year & 6 month & 100.0 & 100.0 & 100.0 & 100.0 \\
10 year & 1 year & 100.0 & 100.0 & 100.0 & 100.0 \\
10 year & 5 year & 100.0 & 100.0 & 100.0 & 100.0 \\
5 year & 6 month & 74.2 & 60.8 & 59.2 & 49.8 \\
5 year & 1 year & 74.6 & 62.6 & 61.2 & 51.2 \\
1 year & 6 month & 11.0 & 5.4 & 8.6 & 4.0 \\
\hline
\end{tabular}


Table A5 (Power)

Two-factor CIR model. 10 years of daily data.

$$
\left(\sigma_{2}=2.5\right)
$$

Panel A: Conditioning variable $=$ short rate

\begin{tabular}{|cc|cc|cc|}
\hline & & \multicolumn{2}{|c|}{ One-sided Test } & \multicolumn{2}{c|}{ Two-sided Test } \\
$Y_{t}$ & $Z_{t}$ & $\alpha=10 \%$ & $\alpha=5 \%$ & $\alpha=10 \%$ & $\alpha=5 \%$ \\
\hline 10 year & 6 month & 98.6 & 97.9 & 99.4 & 99.0 \\
10 year & 1 year & 98.7 & 97.8 & 99.6 & 98.8 \\
10 year & 5 year & 98.3 & 97.5 & 98.5 & 98.2 \\
5 year & 6 month & 90.7 & 86.5 & 88.9 & 83.6 \\
5 year & 1 year & 90.7 & 87.3 & 89.0 & 83.1 \\
1 year & 6 month & 12.2 & 6.6 & 9.8 & 6.2 \\
\hline
\end{tabular}

Panel B: Conditioning variables $=$ short rate, term spread

\begin{tabular}{|cc|cc|cc|}
\hline & & \multicolumn{2}{|c|}{ One-sided Test } & \multicolumn{2}{c|}{ Two-sided Test } \\
$Y_{t}$ & $Z_{t}$ & $\alpha=10 \%$ & $\alpha=5 \%$ & $\alpha=10 \%$ & $\alpha=5 \%$ \\
\hline 10 year & 6 month & 98.2 & 97.3 & 99.0 & 98.0 \\
10 year & 1 year & 98.3 & 97.4 & 98.8 & 97.6 \\
10 year & 5 year & 96.4 & 95.8 & 97.1 & 96.2 \\
5 year & 6 month & 89.1 & 85.7 & 87.4 & 81.7 \\
5 year & 1 year & 88.5 & 84.5 & 85.6 & 80.4 \\
1 year & 6 month & 10.7 & 6.3 & 9.1 & 5.1 \\
\hline
\end{tabular}




\section{Figure Legends}

Figure 1. Daily time series of Spanish Treasury bill and bond yields. The figure shows annual compounded yields on bills and bonds issued by the Spanish Treasury during the full 19932001 period with maturities ranging from one month to ten years.

Figure 2. The slope of the yield curve. The figure shows the historical evolution over time of the difference between the yield on Spanish Treasury ten-year bonds and the yield on one-month bills.

Figure 3. Daily time series of U.S. Treasury bill and bond yields. The figure shows annual compounded yields on bills and bonds issued by the U.S. Treasury during the February 1984-April 2003 period with maturities ranging from three months to ten years.

Figure 4. The slope of the yield curve. The figure shows the historical evolution over time of the difference between the yield on U.S. Treasury ten-year bonds and the yield on three-month bills.

Figure 5. Bond diffusion functions, Spanish market. The figure displays the annualized conditional standard deviation of bond returns for maturities of 3 months to 10 years as functions of the short rate.

Figure 6. Bond diffusion functions U.S. market. The figure displays the annualized conditional standard deviation of bond returns for maturities of 6 months to 10 years as functions of the short rate. 


\section{References}

Ahn, D., R. Dittmar, and A. Gallant. (2002). "Quadratic Term Structure Models: Theory and Evidence." Review of Financial Studies 15, 243-288.

Ä̈t-Sahalia, Y. (1996). "Testing Continuous-Time Models of the Spot Interest Rate." Review of Financial Studies 9, 385-426.

Bandi, F. and P. Phillips. (2003). "Fully Nonparametric Estimation of Scalar Diffusion Models." Econometrica 71, 241-283.

Billingsley, P. (1968). Convergence of Probability Measures. New York, NY: Wiley.

Black, F., and M. Scholes. (1973). "The Pricing of Options and and Corporate Liabilities." Journal of Political Economy 81, 637-654.

Beaglehole, D. and M. Tenney. (1991). "General Solutions of Some Interest Rate-Contingent Claim Pricing Equations." Journal of Fixed Income 1, 69-83.

Beaglehole, D. and M. Tenney. (1992). "A Nonlinear General Equilibrium Model of the Term Structure of Interest Rates: Corrections and Additions.” Journal of Financial Economics 32, $345-454$

Brandt, M. (1999). "Estimating Portfolio and Consumption Choice: A Conditional Euler Equations Approach.” Journal of Finance 54, 1609-1646.

Brandt, M. and D. Chapman. (2002). "Comparing Multifactor Models of the Term Structure." Working Paper, Duke University. 
Brennan, M. and E. Schwartz. (1979). "A Continuous Time Approach to the Pricing of Bonds." Journal of Banking and Finance 3, 133-155.

Brown, S. and P. Dybvig. (1986). "The Empirical Implications of the CIR Theory of the Term Structure of Interest Rates.” Journal of Finance 41, 617-630.

Cabus, P. (1998), "Un Test de Type Kolmogorov-Smirnov dans le Cadre de Comparison de fonctions de Règression.” C. R. Math. Acad. Sci. Paris 327, 939-942.

Cochrane, J. (2001), Asset Pricing. Princeton, NJ: Princeton University Press.

Chan, K., G. Karolyi, F. Longstaff, and A. Sanders. (1992). "An Empirical Comparison of Alternative Models of the Short-Term Interest Rate." Journal of Finance 47, 1209-1228.

Constantinides, G. (1992). "A Theory of the Nominal Term Structure of Interest Rates." Review of Financial Studies 5, 531-552.

Cox, J., J. Ingersoll, and S. Ross. (1985a). "An Intertemporal General Equilibrium Model of Asset Prices." Econometrica 53, 363-384.

Cox, J., J. Ingersoll, and S. Ross. (1985b). "A Theory of the Term Structure of Interest Rates." Econometrica 53, 385-407.

Dai, Q. and K. Singleton. (2000). "Specification Analysis of Affine Term Structure Models." Journal of Finance 55, 1943-1978.

Dai, Q. and K. Singleton. (2002). "Expectation Puzzles, Time-Varying Risk Premia, and Affine Models of the Term Structure." Journal of Financial Economics 63, 415441. 
Dai, Q. and K. Singleton. (2003). "Term Structure Dynamics in Theory and Reality." Review of Financial Studies 16, 631-678.

Delgado, M. A. (1993), "Testing for the Equality of Nonparametric Regression Curves," Statistics and Probability Letters, 17, 199-204.

De Munnik, J. and P. Schotman. (1994). "Cross Sectional Versus Time Series Estimation of Term Structure Models: Empirical Results for the Dutch Bond Market." Journal of Banking and Finance 18, 997-1025.

Díaz, A. and E. Navarro. (2002). "Yield Spreads and Term to Maturity: Default vs. Liquidity." European Financial Management 8, 449-478.

Duffee, G. (2002). "Term Premia and Interest Rate Forecasts in Affine Models." Journal of Finance 57, 405-443.

Duffie, D. and R. Kan. (1996). "A Yield-Factor Model of Interest Rates." Mathematical Finance 6, 379-406.

Ferreira, E., M. Gago and G. Rubio. (2003). "A Semiparametric Estimation of Liquidity Effects on Option Pricing." Spanish Economic Review 5, 1-24.

Ferreira, E. and W. Stute. (2003). "Testing for Differences between Conditional Means in a Time Series Context." Journal of the American Statistical Association, forthcoming.

Jeffrey, A., D. Kristensen, O. Linton, P. Philips, and T. Nguyen. (2004). "Nonparametric Estimation of a Multifactor Heath-Jarrow-Morton model: An integrated approach", Journal of Financial Econometrics 2, 251-289. 
Geyer, A.L.J. and S. Pichler. (1999). "A State-Space Approach to Estimate and Test Multi-Factor Cox-Ingersoll-Ross Models of the Term structure", Journal of Financial Research 22, 107-130.

Gibbons, M. and K. Ramaswamy. (1993). "A Test of the Cox, Ingersoll and Ross Model of the Term Structure.” Review of Financial Studies 6, 619-658.

Hall, P. and J. D. Hart, (1990). "Boostrap Test for Difference between Means in Nonparametric Regression." Journal of the American Statistical Society, 85, 1039-1049.

Härdle, W. (1990). Applied Nonparametric Regression. New York, NY: Cambridge University Press, .

Heath, D., R. Jarrow and A. Morton. (1992). "Bond Pricing and the Term Structure of Interest Rates: A New Methodology." Econometrica 60, 77-105.

Ho, T. S. Y. and S. Lee. (1986). "Term Structure Movements and the Pricing of Interest Rate Contingent Claims." Journal of Finance, 41, 1011-1029.

Koul, H. and A. Schick. (1997). "Testing for the Equality of two Nonparametric Regression Curves," Journal of Statistical Planning and Inference 65, 293-314.

Koul, H. and A. Schick. (2003). "Testing for Superiority among two Regression Curves," Journal of Statistical Planning and Inference 117, 15-33.

Koul, H. and W. Stute. (1999). "Nonparametric Model Checks for Time Series," The Annals of Statistics 27, 204-236.

Litterman, R. and J. Scheinkman. (1991). "Common Factors affecting Bond Returns." Journal of Fixed Income 1, 54-61. 
Longstaff, F. (1989). "A Nonlinear General Equilibrium Model of the Term Structure of Interest Rates." Journal of Finance 23, 1259-1282.

Longstaff, F. (2000). "The Term Structure of Very Short Term Rates: New Evidence for the Expectations Hypothesis.” Journal of Financial Economics 58, 397-415.

Longstaff, F. and E. Schwartz. (1992). "Interest Rate Volatility and the Term Structure: A Two-Factor General Equilibrium Model.” Journal of Finance 47, 1259-1282.

Lu, B. (2000). "An empirical Analysis of the Constantinides Model of the Term Structure." Working paper, University of Michigan.

McCulloch, J. H. (1975). "The Tax-Adjusted yield curve." Journal of Finance 30, 811-830.

Mammen, E. (2000). "Resampling Methods for Nonparametric Regression." Smoothing and Regression, Chapter 14, M.G. Shimek, eds. Wiley.

Marsh, T. and E. Rosenfeld. (1983). "Stochastic Processes for Interest Rates and Equilibrium Bond Prices." Journal of Finance 38, 635-645.

Merton, R. (1973). "Theory of Rational Option Pricing." Bell Journal of Economics and Management Sciences 4, 141-183.

Nowman, K. B. (1997). "Gaussian Estimation of Single-Factor Continuous Time Models of the Term Structure of Interest Rates.” Journal of Finance 52, 1695-1706.

Schaefer, S. M. and E. S. Schwartz. (1984). "A Two-Factor Model of the Term Structure: An Approximate Solution." Journal of Financial and Quantitative Analysis 19, 413-424. 
Stanton, R. (1997). "A Nonparametric Model of Term Structure Dynamics and the Market Price of Interest Rate Risk.” Journal of Finance 52, 1973-2002.

Vasicek, O. (1977). "An Equilibrium Characterization of the Term Structure." Journal of Financial Economics 5, 177-188.

Vasicek, O. A., and H. G. Fong. (1982). "Term Structure Modeling using Exponential Splines." Journal of Finance 2, 339-348. 


\section{Notes}

${ }^{1}$ For a recent survey of dynamic term structure models, see Dai and Singleton (2003).

${ }^{2}$ Note that without measurement error, each daily series has a conditional standard deviation of $\sqrt{1 / 250}=0.0632$.

${ }^{3}$ Although results are not shown in the paper, conclusions do not vary substantially when the continuously compounded three-month rate is taken as a proxy for the instantaneous interest rate.

${ }^{4}$ See McCulloch (1975) for a description of this methodology as applied to yield curve estimation.

${ }^{5}$ These results are not presented for brevity, although they are available from the authors upon request. 


\section{Tables}

\section{Table 1a}

\section{Summary statistics of bill and bond returns, Spanish market}

The table shows the mean and standard deviation of daily returns in percent units. Returns on the $\mathrm{T}$ maturity bill/bond correspond to a strategy of buying every day a zero-coupon bill/bond with $\mathrm{T}$ periods to maturity and selling it on the following day. The sample covers the January 1993-December 2001 period (2,249 observations).

\begin{tabular}{|lcccc|}
\hline & 3 months & 1 year & 5 years & 10 years \\
\hline Mean & 0.0257 & 0.0290 & 0.0484 & 0.0673 \\
Standard Dev. & 0.0425 & 0.1297 & 0.6822 & 1.3876 \\
\hline
\end{tabular}

Table 1b

\section{Summary statistics of bill and bond returns, U.S. market}

The table shows the mean and standard deviation of daily returns in percent units. Returns on the $\mathrm{T}$ maturity bill/bond correspond to a strategy of buying every day a zero-coupon bill/bond with $\mathrm{T}$ periods to maturity and selling it on the following day. The sample covers the April 1982-May 2003 period (5,350 observations).

\begin{tabular}{|lcccc|}
\hline & 6 months & 1 year & 5 years & 10 years \\
\hline Mean & 0.0248 & 0.0268 & 0.0391 & 0.0503 \\
Standard Dev. & 0.0393 & 0.0728 & 0.3504 & 0.6641 \\
\hline
\end{tabular}


Table 2

\section{A test for the single factor hypothesis with the short rate as the conditioning variable, Spanish market (January 1993-December 2002).}

The table shows the test statistics and p-values (in parentheses) for the null hypothesis that the conditional expectation of $Y_{t}$ equals the conditional expectation of $Z_{t}$, where $Y_{t}$ is the daily excess return on the one-year/five-year/ten-year bond over the bond's diffusion, and $Z_{t}$ is the daily excess return on the the six-month/one-year/five-year bond over the bond's diffusion. Under the single factor assumption the null hypothesis must hold for no-arbitrage opportunities to exist between any two different bonds. Two different alternatives are considered: the conditional expectation of $Y_{t}$ is different from the conditional expectation of $Z_{t}$ and the conditional expectation of $Y_{t}$ is larger than the conditional expectation of $Z_{t}$. The diffusion coefficient has been estimated conditional on the short rate, which we assume to fully capture the state of the system.

\begin{tabular}{cccc}
\hline$Y_{t}$ & $Z_{t}$ & $H_{a}: E_{t}\left(Y_{t}\right)-E_{t}\left(Z_{t}\right)>0$ & $H_{a}: E_{t}\left(Y_{t}\right)-E_{t}\left(Z_{t}\right) \neq 0$ \\
\hline 10 year & 3 month & 1.3306 & 1.3306 \\
10 year & 1 year & 0.8918 & 0.8918 \\
10 year & 5 year & 0.4707 & 0.4707 \\
5 year & 3 month & 1.2997 & 1.2997 \\
5 year & 1 year & 0.6729 & 0.6729 \\
1 year & 3 month & 1.2397 & 1.2397 \\
\hline
\end{tabular}


Table 3

A test for the single factor hypothesis with the short rate and the term spread as conditioning variables, Spanish market (January 1993-December 2002).

The table shows the test statistics and p-values (in parentheses) for the null hypothesis that the conditional expectation of $Y_{t}$ equals the conditional expectation of $Z_{t}$, where $Y_{t}$ is the daily excess return on the one-year/five-year/ten-year bond over the bond's diffusion, and $Z_{t}$ is the daily excess return on the the six-month/one-year/five-year bond over the bond's diffusion. Under the single factor assumption the null hypothesis must hold for no-arbitrage opportunities to exist between any two different bonds. Two different alternatives are considered: the conditional expectation of $Y_{t}$ is different from the conditional expectation of $Z_{t}$ and the conditional expectation of $Y_{t}$ is larger than the conditional expectation of $Z_{t}$. The diffusion coefficient has been estimated conditional on the short rate and the term spread,, which we assume to jointly capture the state of the system.

\begin{tabular}{cccc}
\hline$Y_{t}$ & $Z_{t}$ & $H_{a}: E_{t}\left(Y_{t}\right)-E_{t}\left(Z_{t}\right)>0$ & $H_{a}: E_{t}\left(Y_{t}\right)-E_{t}\left(Z_{t}\right) \neq 0$ \\
\hline 10 year & 3 month & 1.2897 & 1.2897 \\
10 year & 1 year & 0.8414 & 0.8414 \\
10 year & 5 year & 0.4350 & 0.4350 \\
5 year & 3 month & 1.2745 & 1.2745 \\
5 year & 1 year & 0.6512 & 0.6512 \\
1 year & 3 month & 1.2007 & 1.2007 \\
\hline
\end{tabular}


Table 4

A test for the single factor hypothesis with the short rate as the conditioning variable, U.S. market (April 1982-May 2003).

The table shows the test statistics and p-values (in parentheses) for the null hypothesis that the conditional expectation of $Y_{t}$ equals the conditional expectation of $Z_{t}$, where $Y_{t}$ is the daily excess return on the one-year/five-year/ten-year bond over the bond's diffusion, and $Z_{t}$ is the daily excess return on the the six-month/one-year/five-year bond over the bond's diffusion. Under the single factor assumption the null hypothesis must hold for no-arbitrage opportunities to exist between any two different bonds. Two different alternatives are considered: the conditional expectation of $Y_{t}$ is different from the conditional expectation of $Z_{t}$ and the conditional expectation of $Y_{t}$ is larger than the conditional expectation of $Z_{t}$. The diffusion coefficient has been estimated conditional on the short rate, which we assume to fully capture the state of the system.

\begin{tabular}{cccc}
\hline$Y_{t}$ & $Z_{t}$ & $H_{a}: E_{t}\left(Y_{t}\right)-E_{t}\left(Z_{t}\right)>0$ & $H_{a}: E_{t}\left(Y_{t}\right)-E_{t}\left(Z_{t}\right) \neq 0$ \\
\hline 10 year & 6 month & 0.2632 & 1.2551 \\
10 year & 1 year & 0.1479 & 1.6497 \\
10 year & 5 year & 0.1057 & 1.2301 \\
5 year & 6 month & 0.3764 & 0.9177 \\
5 year & 1 year & 0.2689 & 1.2176 \\
1 year & 6 month & 0.5710 & 0.5710 \\
\hline
\end{tabular}


Table 5

A test for the single factor hypothesis with the short rate and the term spread as conditioning variables, U.S. market (April 1982-May 2003).

The table shows the test statistics and p-values (in parentheses) for the null hypothesis that the conditional expectation of $Y_{t}$ equals the conditional expectation of $Z_{t}$, where $Y_{t}$ is the daily excess return on the one-year/five-year/ten-year bond over the bond's diffusion, and $Z_{t}$ is the daily excess return on the the six-month/one-year/five-year bond over the bond's diffusion. Under the single factor assumption the null hypothesis must hold for no-arbitrage opportunities to exist between any two different bonds. Two different alternatives are considered: the conditional expectation of $Y_{t}$ is different from the conditional expectation of $Z_{t}$ and the conditional expectation of $Y_{t}$ is larger than the conditional expectation of $Z_{t}$. The diffusion coefficient has been estimated conditional on the short rate and the term spread,, which we assume to jointly capture the state of the system.

\begin{tabular}{cccc}
\hline$Y_{t}$ & $Z_{t}$ & $H_{a}: E_{t}\left(Y_{t}\right)-E_{t}\left(Z_{t}\right)>0$ & $H_{a}: E_{t}\left(Y_{t}\right)-E_{t}\left(Z_{t}\right) \neq 0$ \\
\hline 10 year & 6 month & 0.2136 & 1.4008 \\
10 year & 1 year & 0.1558 & 1.7398 \\
10 year & 5 year & 0.1134 & 1.2751 \\
5 year & 6 month & 0.3737 & 1.0558 \\
5 year & 1 year & 0.2595 & 1.2975 \\
1 year & 6 month & 0.4612 & 0.4612 \\
\hline
\end{tabular}


Table 6

A test for the single factor hypothesis with the short rate as the conditioning variable, U.S. market (February 1962-March 2004).

The table shows the test statistics and p-values (in parentheses) for the null hypothesis that the conditional expectation of $Y_{t}$ equals the conditional expectation of $Z_{t}$, where $Y_{t}$ is the daily excess return on the one-year/five-year/ten-year bond over the bond's diffusion, and $Z_{t}$ is the daily excess return on the the six-month/one-year/five-year bond over the bond's diffusion. Under the single factor assumption the null hypothesis must hold for no-arbitrage opportunities to exist between any two different bonds. Two different alternatives are considered: the conditional expectation of $Y_{t}$ is different from the conditional expectation of $Z_{t}$ and the conditional expectation of $Y_{t}$ is larger than the conditional expectation of $Z_{t}$. The diffusion coefficient has been estimated conditional on the short rate, which we assume to fully capture the state of the system.

\begin{tabular}{cccc}
\hline$Y_{t}$ & $Z_{t}$ & $H_{a}: E_{t}\left(Y_{t}\right)-E_{t}\left(Z_{t}\right)>0$ & $H_{a}: E_{t}\left(Y_{t}\right)-E_{t}\left(Z_{t}\right) \neq 0$ \\
\hline 10 year & 6 month & 0.1801 & 1.5744 \\
10 year & 1 year & 0.2163 & 1.6263 \\
10 year & 5 year & 0.0979 & 1.1372 \\
5 year & 6 month & 0.1646 & 1.1877 \\
5 year & 1 year & 0.2069 & 1.1524 \\
1 year & 6 month & 0.1295 & 0.6186 \\
\hline
\end{tabular}


Table 7

A test for the single factor hypothesis with the short rate and the term spread as conditioning variables, U.S. market (February 1962-March 2004).

The table shows the test statistics and p-values (in parentheses) for the null hypothesis that the conditional expectation of $Y_{t}$ equals the conditional expectation of $Z_{t}$, where $Y_{t}$ is the daily excess return on the one-year/five-year/ten-year bond over the bond's diffusion, and $Z_{t}$ is the daily excess return on the the six-month/one-year/five-year bond over the bond's diffusion. Under the single factor assumption the null hypothesis must hold for no-arbitrage opportunities to exist between any two different bonds. Two different alternatives are considered: the conditional expectation of $Y_{t}$ is different from the conditional expectation of $Z_{t}$ and the conditional expectation of $Y_{t}$ is larger than the conditional expectation of $Z_{t}$. The diffusion coefficient has been estimated conditional on the short rate and the term spread,, which we assume to jointly capture the state of the system.

\begin{tabular}{cccc}
\hline$Y_{t}$ & $Z_{t}$ & $H_{a}: E_{t}\left(Y_{t}\right)-E_{t}\left(Z_{t}\right)>0$ & $H_{a}: E_{t}\left(Y_{t}\right)-E_{t}\left(Z_{t}\right) \neq 0$ \\
\hline 10 year & 6 month & 0.1870 & 1.8886 \\
10 year & 1 year & 0.2474 & 1.8903 \\
10 year & 5 year & 0.1123 & 1.3038 \\
5 year & 6 month & 0.1623 & 1.4413 \\
5 year & 1 year & 0.2298 & 1.3355 \\
1 year & 6 month & 0.1428 & 0.6924 \\
\hline
\end{tabular}




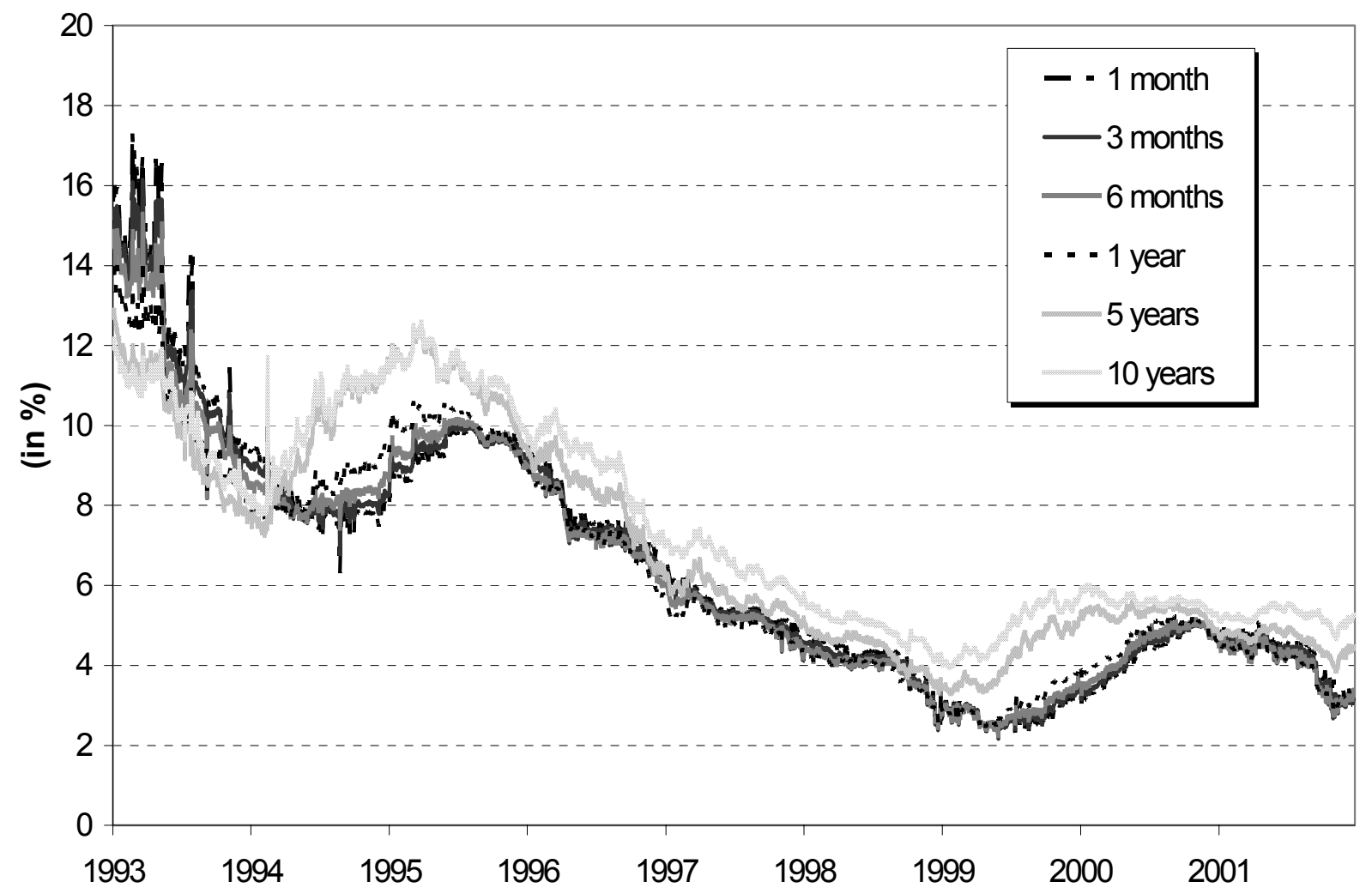

Figure 1: 


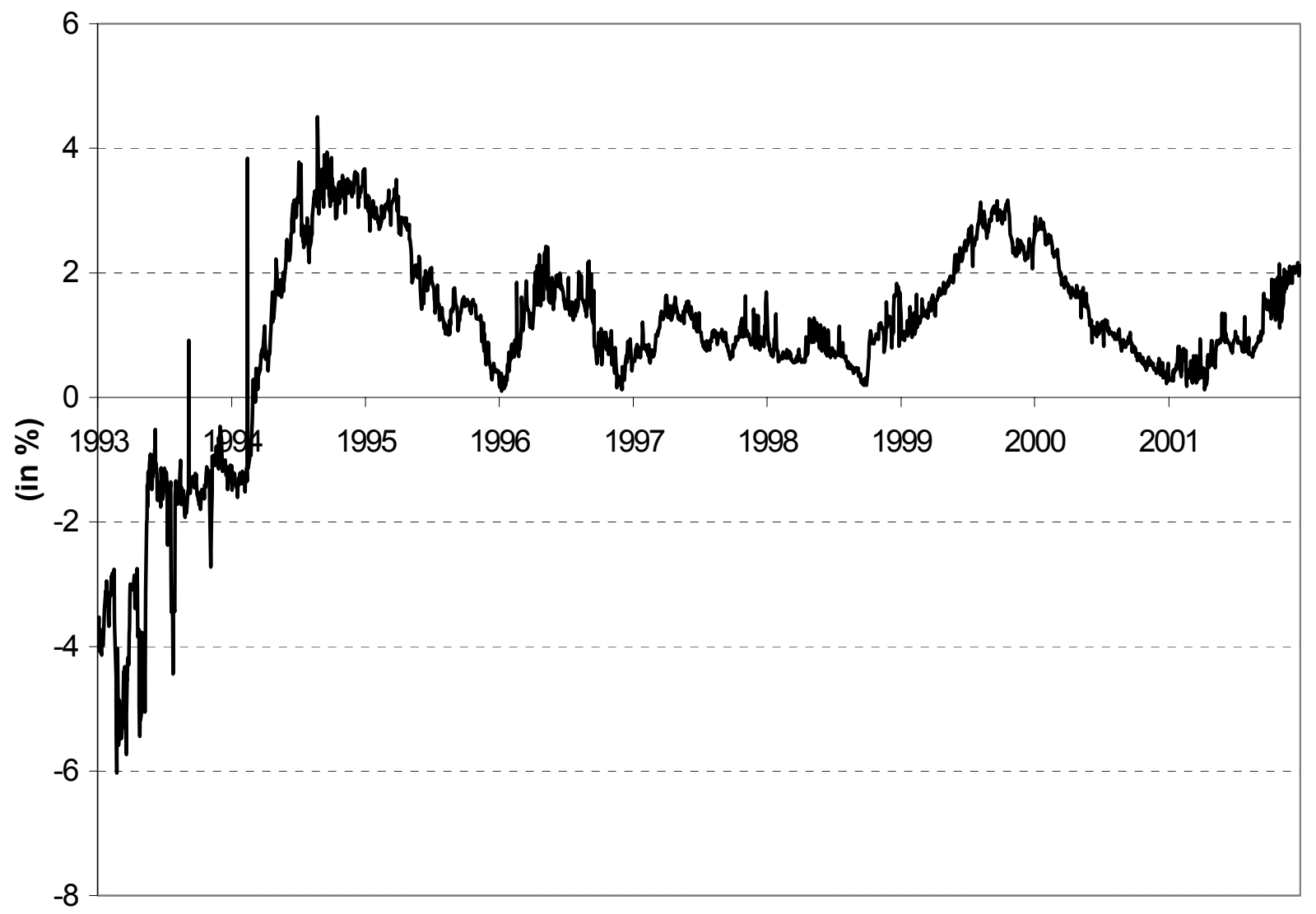

Figure 2: 


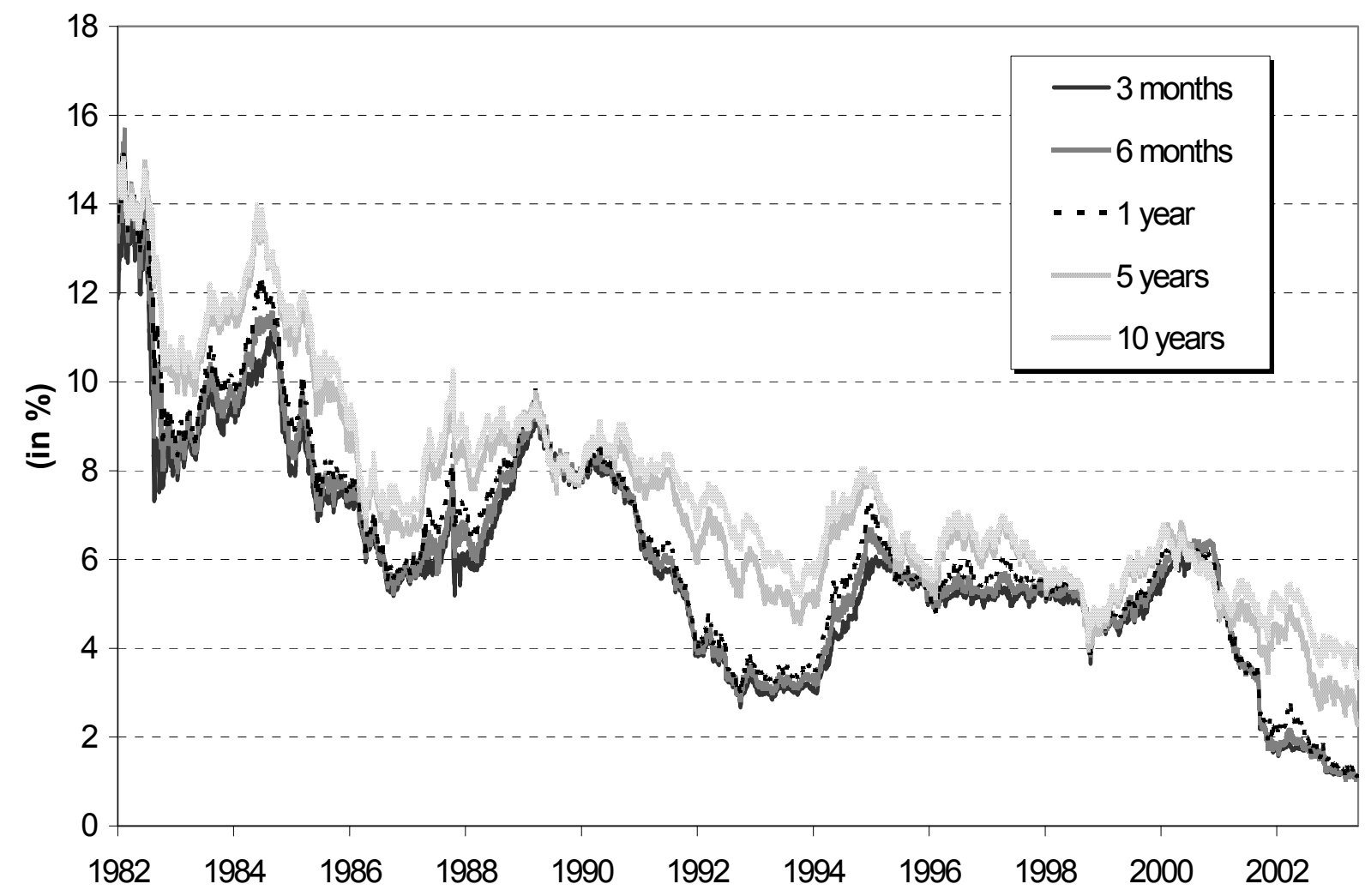

Figure 3: 


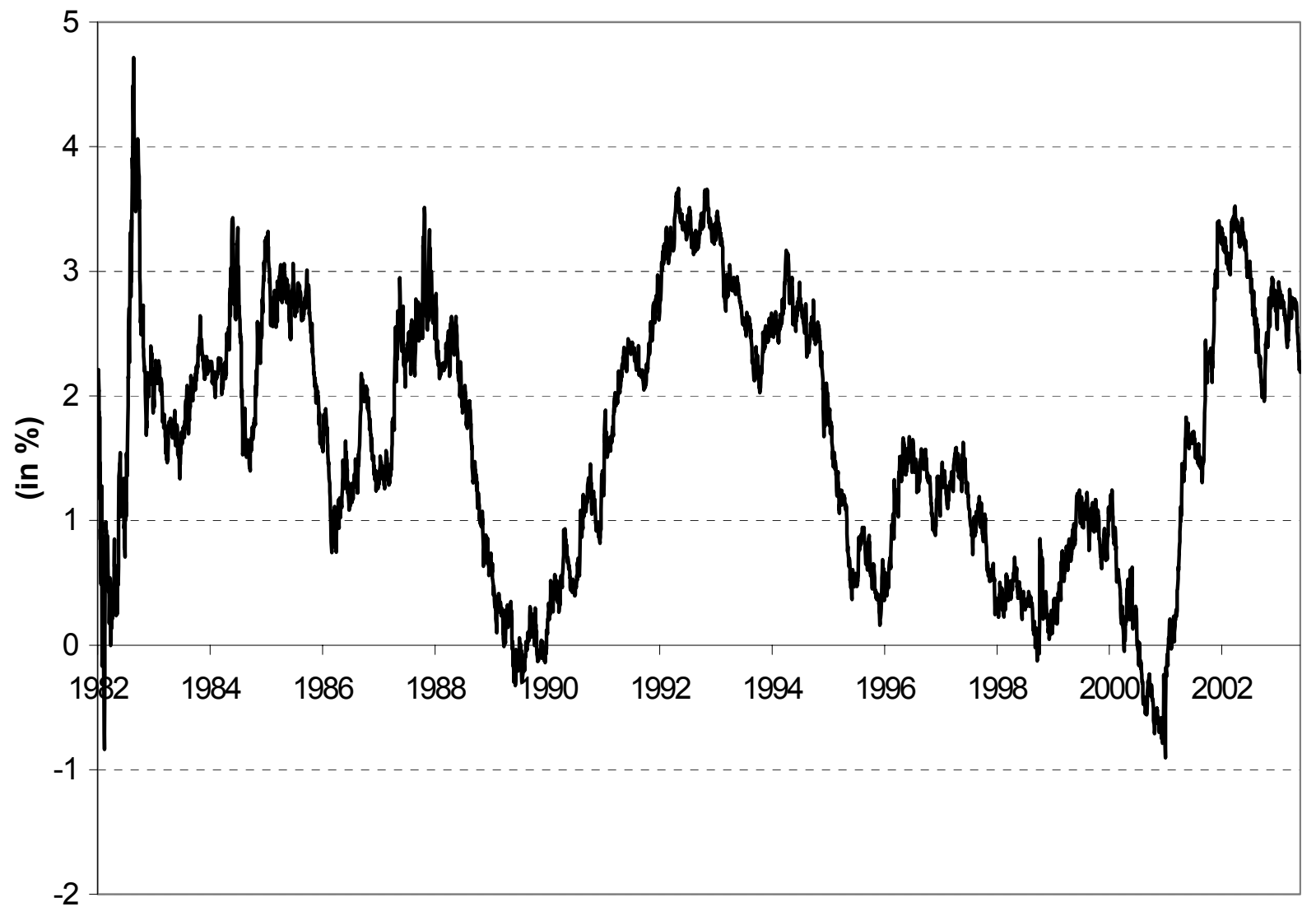

Figure 4: 


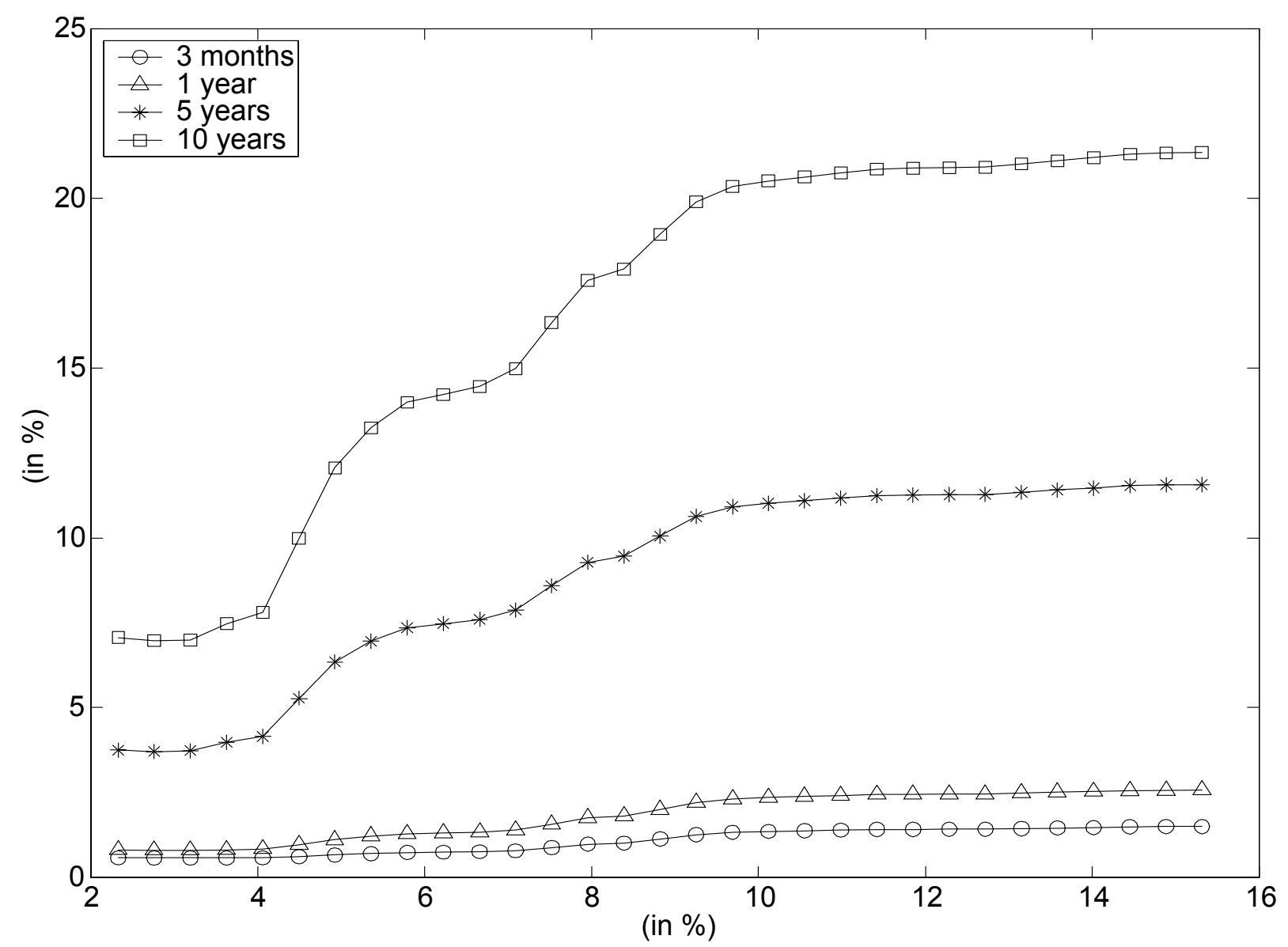

Figure 5: 


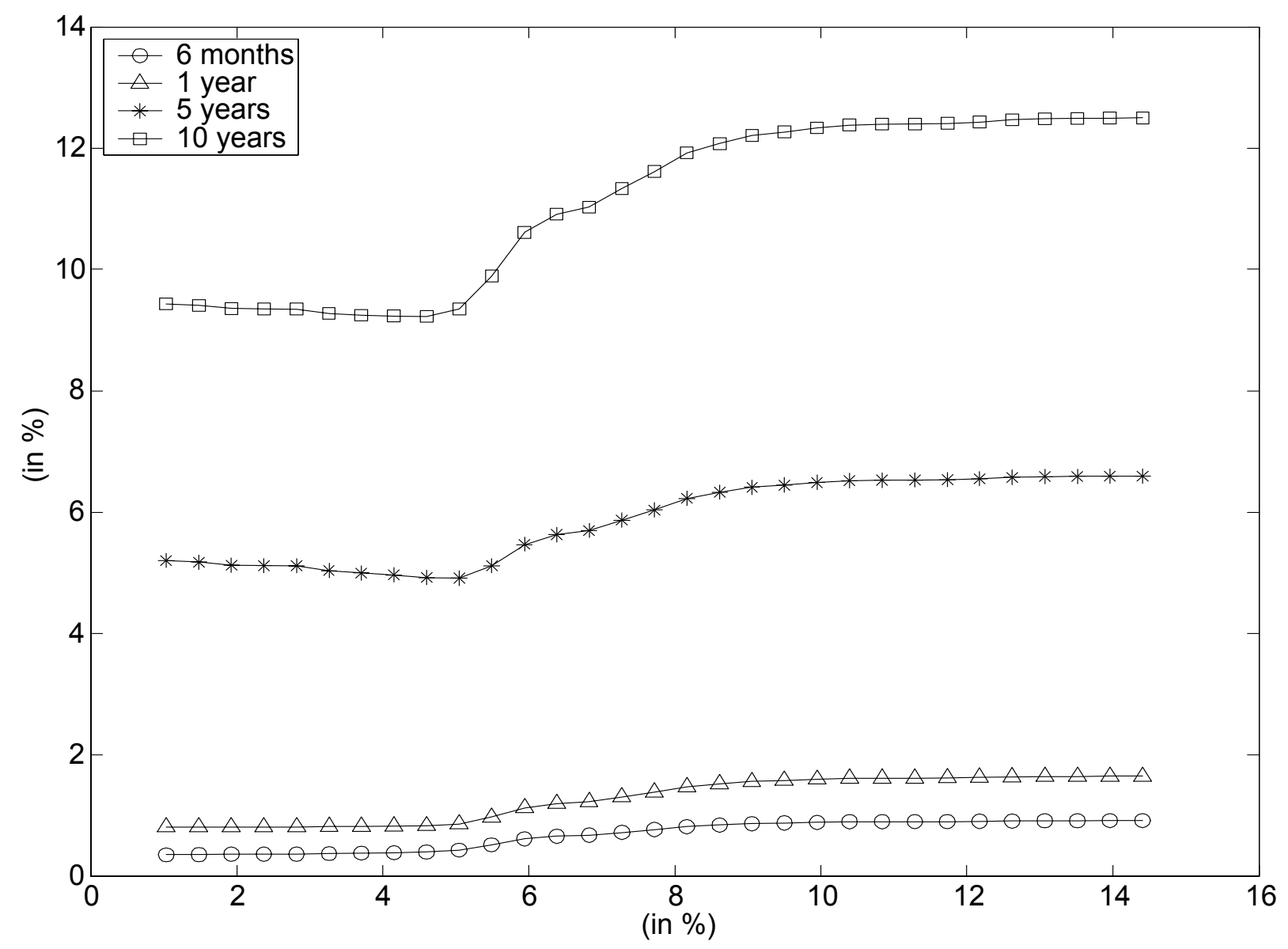

Figure 6: 